\title{
The Effect of Moringa Oleifera Leaves on Chicken Meat Composition and Meat Quality
}

\author{
Elsayed Mickdam ${ }^{*}$, Sara Alwaleed ${ }^{1}$, Mohammed Madany $^{2}$ and Abdelbaset Sayed ${ }^{3}$ \\ ${ }^{1}$ Nutrition and Clinical Nutrition Department, Faculty of Veterinary Medicine, South Valley University, Qena, Egypt \\ ${ }^{2}$ Food hygiene Department, Faculty of Veterinary Medicine, South Valley University, Qena, Egypt \\ ${ }^{3}$ Animal and Clinical Nutrition Department, Faculty of Veterinary Medicine, Assuit University, Assuit, Egypt \\ *Corresponding author: e.mickdam@vet.svu.edu.eg
}

\begin{abstract}
\begin{tabular}{llll}
\hline Article History: 21-345 Received: 27-Jun-21 & Revised: 28-Jul-21 & Accepted: 16-Aug-21
\end{tabular}
\section{ABSTRACT}

The meat of the broiler chickens has created a huge demand among consumers. Phytobiotics attracted the attention as natural feed additives to improve meat quality and consumer acceptance. This study was conducted to investigate whether addition of Moringa Oleifera (MO) in broiler diets in different levels improve meat quality and meat chemical composition of broiler chickens. A total 150 a-day old broiler chicks (Cobb) were randomly distributed into 5 equal groups. Diets were formulated to contain approximately the same level of crude protein (CP) and metabolizable energy. In the first group (control), birds were kept on basal diet. Chicks in second, third, fourth and fifth groups were fed on the basal diets supplemented with 1, 3,5 and 7\% MO leaves, respectively. Meat samples from the humanely killed birds (on day 42) were collected to measure $\mathrm{pH}$ and cholesterol level. Part of the meat samples was prepared for chemical analysis and Thiobarbituric acid number (TBA). The $\mathrm{CP}$ level was the highest in the thigh $(\mathrm{P}=0.002)$ and breast muscles $(\mathrm{P}=0.007)$ of birds fed 3\% MO. In the same way, addition of 3\% MO to the diet decreased the fat in both thigh and breast muscles $(\mathrm{P}<0.001)$. The $\mathrm{pH}$ of breast muscles was suppressed in birds fed $3 \% \mathrm{MO}$ diet $(\mathrm{P}<0.05)$. The addition of $7 \% \mathrm{MO}$ to the diet decreased $(\mathrm{P}<0.001)$ cholesterol level in breast muscle of birds. It was concluded that addition of MO leaves to the diet of broiler chicks improved meat quality and composition.
\end{abstract}

Key words: Phytobiotics, Moringa Oleifera, Broiler chickens, Cholesterol, Meat quality

\section{INTRODUCTION}

Broiler chickens are mainly reared for meat production because of their short production period. Moreover, the meat of the broiler chickens has created a huge demand among consumers because it is a good source of protein, minerals and vitamins. In addition, broiler meat has low lipid content making it a healthier consumer option. Therefore, broilers meat becomes a major part of human meal. This consequently, increased the demand for higher annual meat production worldwide (Arshad et al. 2016; Santhi et al. 2020). However, consumers are interested in meat that can contribute to their personal satisfaction. In addition, consumer demand has also shifted from the whole bird to its processed parts, increasing further the value of meat yield and its quality attributes. Therefore, efforts are being made to improve meat quality and increase its storage capacity to achieve consumer preference.

The major challenge facing in broiler production is the occurrence of infectious diseases due to poor biosecurity.
For decades, antibiotics have been used in broiler feed to prevent and treat diseases and to improve performance and feed efficacy (Roth et al. 2019). The non-therapeutic application of antibiotics increases the residual accumulation rather than medical use thus increases the risk of antimicrobial resistance. Moreover, in 2006 the European Union prohibited antibiotic in animal diets due to toxicity problems and development of microbial resistance. Thus, meat production from broiler chicken without using antibiotics is crucial to protect human health against antimicrobial resistance (Haque et al. 2020). Moreover, consumers are concerned not only about nutritional content and flavor but also antibiotic residue. Consequently, there was also a need to find available alternatives for growth promotion and feeding efficiency.

Phytobiotics have gained interest as alternatives to antibiotics (Alagawany et al. 2021) and use of phytobiotics in poultry has been linked to a variety of growth and health promotion properties. The mode of action of phytobiotics is described through improving gut histology and gut

Cite This Article as: Mickdam E, Alwaleed S, Madany M, Sayed A, 2022. The effect of Moringa Oleifera leaves on chicken meat composition and meat quality. International Journal of Veterinary Science 11(2): 201-206. https://doi.org/10.47278/journal.ijvs/2021.094 
health, stabilizing intestinal microbime and reduction of inflammation and modifying digestive secretions (Gilani et al. 2021; Krauze et al. 2021). The phytobiotics also improve carcass meat safety and quality through reducing microbial load and improving sensory characteristics (Prabakar et al. 2016).

Moringa Oleifera (MO) is a valuable plant showed multiple potential effects including growth promotion, antimicrobial and antioxidant effects (Gupta et al. 2018; Dhakad et al. 2019; Gehad et al. 2020). Due to its antimicrobial effect and pharmacological properties, MO could be used as alternatives to growth promoters for poultry (Mehta et al. 2003; Shin et al 2018). Therefore, the effect of MO leaves meal on performance, carcass yield, gut integrity and nutrient utilization have been investigated at different inclusion levels either as an alternative protein source or as phytogenic feed additives alone and/or in combination with extracts from other plants (Zanu et al. 2012; Kholif et al. 2018; Mahmoud et al. 2019; Zhang et al. 2019; Degla et al. 2021). However, the optimal level of MO leaves as a nutritional supplement has not yet been determined (Hassan et al. 2016). In addition, there are few publications regarding the effect of feeding MO leaves on chemical composition and cholesterol level in broilers meat (Mahfuz and Piao 2019). Therefore, the aim of this study was to assess the beneficial effects of MO leaves meal on meat composition and cholesterol level in broiler meat. We hypothesized that the use of $M$. Oleifera leave meal (MOLM) in small concentration might improve composition and quality of broilers meat.

\section{MATERIALS AND METHODS}

\section{Bio-Ethics Permission}

All experimental procedures, bird handling and treatment were approved by Ethical Committee of Animal Care and Welfare (No. VetEg. 918_201-2018), Faculty of Veterinary Medicine, South Valley University (ECREACU-V-SVU).

\section{Birds, Diets and Experimental Design}

The experiment was conducted at the research farm of Faculty of Veterinary Medicine, South Valley University, Qena, Egypt. This study used 150 a-day-old, unsexed broiler chicks (Cobb, obtained from a local commercial hatchery). Birds were wing-tagged and randomly distributed in a complete randomized design with 5 treatments and 3 replicates with 10 birds in each replicate. The feeding plan was designed as previously described (Alwaleed et al. 2020). Briefly, the birds were fed isoenergetic (3200 Kcal $/ \mathrm{kg}$ metabolizable energy) and isonitrogenous diets $(23,20$ and $18 \%$ crude protein for starter, grower and finisher, respectively). The diets were formulated using commercially available ingredients based on corn grain and soybean oil meal. All experimental diets meet the minimum nutrient requirements recommended for Cobb broilers and offered in a mash form. Control diet (Con) was without addition of MOLM. Experimental diets were supplemented with 1, 3, 5 and 7\% MOLM (M1, M3, M5, and M7, respectively). Ingredients and nutrient composition of the experimental diets are shown in Table 1. The birds were kept in experimental chambers under the recommended optimal conditions of temperature, humidity and ventilation. Food and water were offered ad-libitum during the whole experimental period. The experimental diets were prepared as described previously (Alwaleed et al. 2020). In details, MO leaves were collected from local farm at Qena governorate and spread out under the shade to dry at $35^{\circ} \mathrm{C}$ for $5 \mathrm{~d}$. After drying, the leaves were crushed to a fine powder and preserved for further analysis. The proximate analysis of the leaves for moisture, $\mathrm{CP}$, crude fat as ether extract (EE), ash and fiber were performed as per the slandered method (AOAC 2005).

\section{Sampling, Chemical Analysis and Meat pH, TBA and Cholesterol Levels}

At the last day of the experiment, 3 birds were randomly selected from each group and humanely killed after fasting overnight. Afterwards, the birds were scalded, de-feathered and carcasses were eviscerated. Meat samples from breast and thigh collected taken for different analysis. Part of meat samples were minced, dried, homogenized and chemically analyzed for dry matter (DM), CP, EE and ash according to the standard methods (AOAC 2005). In details, DM was analyzed by oven drying overnight at $100^{\circ} \mathrm{C}$ and $\mathrm{CP}$ was determined by the Kjeldahl's method while crude fat was analyzed as EE by using Soxhlet extractor and ash by combustion of samples at $580^{\circ} \mathrm{C}$ overnight. Energy contribution (kcal/100g meat) was calculated according to the method described by Nkukwana et al. (2015).

The $\mathrm{pH}$ value of meat samples was determined by using an electric pH meter (Bayer Model 6020, USA). Samples were prepared for cholesterol analysis (only for breast meat) including extraction of fat from meat tissue and preparation of that extract for analysis (Bligh and Dyer 1959; Naeemi et al. 1995). Afterwards, the procedures of diagnostic cholesterol reagent (CHOD-PAP, spectrum, S.A.E.) was used to determine cholesterol level in meat samples (Pasin et al. 1998). The TBA values were determined according to the method described by Vyncke (1970). The effects of the same MOLM on growth performance, carcass characteristics and blood parameters in our companion study was evaluated (Alwaleed et al. 2020).

\section{Statistical Analysis}

Data were analyzed using analysis of variance with the Graph-Pad Prism (GraphPad Software, San Diego, CA, USA). All values were presented as mean \pm SD Significance was declared at $\mathrm{P}<0.05$ and a trend was set at $\mathrm{P}<0.05$ and $\mathrm{P}<0.10$. Tukey's test was used for comparisons among means.

\section{RESULTS}

\section{Chemical Composition of Breast and Thigh Meat}

The results indicated that supplementation of MOLM significantly increased $(\mathrm{P}<0.01) \mathrm{DM}$ and $\mathrm{CP}$ and tend to increase $(\mathrm{P}=0.08)$ ash content of breast meat. On the other hand, EE was significantly lower in the breast meat compared to control group fed basal diet (Table 2). The $\mathrm{CP}$ percentage of breast meat for M1 and M3 groups was higher $(\mathrm{P}<0.05)$ than that of the control, M5 and M7 groups. The EE content in the breast meat for Control, M1 and M7 $(\mathrm{P}<0.05)$ was higher than those of the M3 and M5 groups. Supplementation of MOLM tend to $(\mathrm{P}=0.08)$ 
Int J Vet Sci, 2022, 11(2): 201-206.

Table 1: Physical and chemical composition (\%) of the experimental diets prepared by incorporating of Moringa Oleifera leave meal (MOLM)

\begin{tabular}{|c|c|c|c|c|c|c|c|c|c|c|c|c|c|c|c|}
\hline \multirow[t]{2}{*}{ Groups ${ }^{1}$} & \multicolumn{5}{|c|}{ Starter diets } & \multicolumn{5}{|c|}{ Grower diets } & \multicolumn{5}{|c|}{ Finisher diets } \\
\hline & Con & M1 & M3 & M5 & M7 & Con & M1 & M3 & M5 & M7 & Con & M1 & M3 & M5 & M7 \\
\hline \multicolumn{16}{|l|}{$\overline{\text { Feed stuff (\%) }}$} \\
\hline Yell & 5.7 & 46.3 & 46.0 & 45.7 & 45.4 & 59.00 & 58.80 & 58.60 & 58.50 & 58.40 & 65.44 & 65.24 & 65.04 & 64.94 & 54.8 \\
\hline & .0 & 42.5 & 41.0 & 39.5 & 38.0 & 33.00 & 32.30 & 30.70 & 29.00 & 27.30 & 26.50 & 25.8 & 4.20 & 2.50 & 0.8 \\
\hline & & 6.55 & 6.35 & 6.15 & 5.95 & 4.79 & 4.69 & 4.4 & 4.29 & 4.09 & 4.69 & 4.59 & 4.39 & 4.19 & 3.99 \\
\hline $\mathrm{MO}$ & 0 & 1 & 3 & 5 & 7 & 0 & 1 & 3 & 5 & 7 & 0 & & 3 & - & \\
\hline in & & 1.44 & 1.44 & 1.44 & 1.44 & 1.47 & 1.47 & 1.47 & 1.47 & 1.47 & 1.50 & 1.50 & .50 & 1.50 & .50 \\
\hline i & & 1.4 & 1.4 & 1.4 & 1.4 & 1.00 & 1.00 & 1.00 & 1.00 & 1.00 & 1.10 & 1.10 & .10 & 1.10 & .10 \\
\hline on & 0.40 & 0.40 & 0.40 & 0.40 & 0.40 & 0.40 & 0.40 & 0.40 & 0.40 & 0.40 & 0.40 & 0.40 & .40 & 0.40 & .40 \\
\hline & 30 & 0.30 & 0.30 & 0.30 & 0.30 & 0.30 & 0.30 & 0.30 & 0.30 & 0.30 & 0.30 & 0.30 & .30 & 0.30 & 0.30 \\
\hline Dethionine & 0.11 & 0.11 & 0.11 & 0.11 & 0.11 & 0.04 & 0.04 & 0.04 & 0.04 & 0.04 & 0.07 & 0.07 & 0.07 & 0.07 & 0.07 \\
\hline \multicolumn{16}{|l|}{ Calculated analysis } \\
\hline ruc & .96 & 23.0 & 23.1 & 23.1 & 23.1 & 20.06 & 20.09 & 20.09 & 20.08 & 20.06 & 18.00 & 18.04 & 18.05 & 18.03 & 18.0 \\
\hline ME & 3095.2 & 3094 & 3099 & 3103 & 3108 & 3124 & 3126 & 3131 & 3138 & 3145 & 3186 & 3188 & 3194 & 3201 & 3208 \\
\hline alc & 00 & 1.03 & 1.10 & 1.16 & 1.23 & 0.9 & 0.92 & 0.99 & 1.01 & 1.10 & 0.91 & 0.93 & 1.00 & 1.07 & 1.13 \\
\hline va & 0.46 & 0.46 & 0.46 & 0.46 & 0.47 & 0.37 & 0.37 & 0.37 & 0.37 & 0.37 & 0.38 & 0.38 & 0.38 & 0.38 & 0.38 \\
\hline & & 0.49 & 0.50 & 0.51 & 0.52 & 0.37 & 0.38 & 0.39 & 0.40 & 0.41 & 0.37 & 0.37 & 0.39 & 0.40 & 0.41 \\
\hline Lysine (\%) & 1.37 & 1.40 & 1.45 & 1.45 & 1.47 & 1.11 & 1.13 & 1.15 & 1.17 & 1.19 & 094 & 0.96 & 0.98 & 1.00 & 1.02 \\
\hline
\end{tabular}

Control group fed basal diet without any supplementation. M1, M2, M3 and M4 groups fed basal diet supplemented with 1, 3, 5 and 7\% MOLM, respectively. Each 3kg contained: Vit. A-1200000IU; Vit. D $3-300000 I U ;$ Vit. E-700mg; Vit. k3-500mg; Vit. B1-500mg; Vit. $\mathrm{B}_{2}-200 \mathrm{mg}$; Vit. B 6 -600mg; Vit. B $12-3 \mathrm{mg}$; Vit. C-450mg; Niacin, Methionine, Magnesium sulphate and Copper sulphate each 3000mg; Pantothenic acid-670mg; Folic acid-300mg; Biotin-6 mg; Choline chloride and Iron sulphate each 10000mg; Zinc sulphate-1800mg; Cobalt sulphate-300mg.

Table 2: Meat chemical composition (\%) in dry base matter of broilers as influenced by different dietary treatments of Moringa Oleifera leave meal (MOLM)

\begin{tabular}{lcccccc}
\hline Item & \multicolumn{5}{c}{ Groups $^{1}$} & P Value \\
\cline { 2 - 5 } & Control & M1 & M3 & M5 & M7 \\
\hline Breast meat & & & & & & \\
DM & $28.93 \pm 0.114 \mathrm{~b}$ & $29.22 \pm 0.158 \mathrm{ab}$ & $29.37 \pm 0.160 \mathrm{ab}$ & $29.91 \pm 0.096 \mathrm{a}$ & $29.64 \pm 240 \mathrm{ab}$ & 0.013 \\
CP & $83.48 \pm 0.278 \mathrm{~b}$ & $84.81 \pm 0.064 \mathrm{a}$ & $84.87 \pm 0.162 \mathrm{a}$ & $83.38 \pm 0.0153 \mathrm{~b}$ & $82.72 \pm 0.335 \mathrm{~b}$ & $<0.001$ \\
EE & $9.02 \pm 0.242 \mathrm{a}$ & $8.95 \pm 0.087 \mathrm{a}$ & $8.23 \pm 0.062 \mathrm{~b}$ & $7.98 \pm 0.117 \mathrm{~b}$ & $9.31 \pm 0.067 \mathrm{a}$ & 0.001 \\
Ash & $5.98 \pm 0.051$ & $6.06 \pm 0.061$ & $6.61 \pm 0.270$ & $6.55 \pm 0.092$ & $6.25 \pm 0.237$ & 0.086 \\
EC & $394.3 \pm 1.05 \mathrm{a}$ & $393.6 \pm 0.611 \mathrm{a}$ & $387.9 \pm 1.22 \mathrm{~b}$ & $386.9 \pm 0.231 \mathrm{~b}$ & $394.8 \pm 1.01 \mathrm{a}$ & 0.002 \\
Thigh meat & & & & & & \\
DM & $28.96 \pm 0.040 \mathrm{~b}$ & $29.84 \pm 0.059 \mathrm{a}$ & $29.64 \pm 0.129 \mathrm{a}$ & $29.85 \pm 0.069 \mathrm{a}$ & $29.91 \pm 0.076 \mathrm{a}$ & $<0.001$ \\
CP & $82.92 \pm 0.073 \mathrm{bc}$ & $83.65 \pm 0.152 \mathrm{~b}$ & $84.79 \pm 0.218 \mathrm{a}$ & $83.17 \pm 0.260 \mathrm{bd}$ & $82.55 \pm 0.281 \mathrm{~cd}$ & 0.0002 \\
EE & $8.80 \pm 0.155 \mathrm{ab}$ & $9.82 \pm 0.345 \mathrm{a}$ & $8.05 \pm 0.180 \mathrm{~b}$ & $9.68 \pm 0.093 \mathrm{a}$ & $9.39 \pm 0.287 \mathrm{a}$ & 0.001 \\
Ash & $6.04 \pm 0.076$ & $5.90 \pm 0.044$ & $6.74 \pm 0.153$ & $6.13 \pm 0.235$ & $6.31 \pm 0.389$ & 0.144 \\
EC & $393.0 \pm 0.907 \mathrm{ab}$ & $398.7 \pm 1.76 \mathrm{a}$ & $386.5 \pm 1.45 \mathrm{~b}$ & $397.1 \pm 0.518 \mathrm{a}$ & $395.0 \pm 2.91 \mathrm{a}$ & 0.004 \\
\hline
\end{tabular}

Control group fed basal diet without any supplementation. M1, M2, M3 and M4 groups fed basal diet supplemented with 1, 3, 5 and 7\%

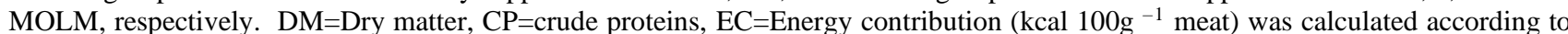
Nkukwana et al. (2015). Mean+SD of treatments sharing no common alphabets are significantly different $(\mathrm{P}<0.05)$.

increase the ash content of breast meat without any differences between the dietary treatments. On the contrary, the breast meat of birds fed control diet showed higher energy contribution than those of the supplemented groups $(\mathrm{P}=0.002)$. The highest and the lowest inclusion level of MOLM (M1 and M3) did not change the energy content of breast meat, while the inclusion of $3 \%$ MOLM significantly reduced $(\mathrm{P}<0.05)$ energy content of the meat.

The composition of thigh meat followed the same pattern (DM and CP) but the ash content was not affected by supplementation of MOLM. On the other hand, EE was increased significantly $(\mathrm{P}=0.001)$ with supplementation of MOLM (Table 2). The CP content of thigh muscle was higher for M3 than those of the other groups $(\mathrm{P}<0.05)$. On the contrary, the content of EE of thigh meat was the lowest in M3 group while other means were similar to each other $(\mathrm{P}<0.05)$. Unlike results of breast meat, the supplementation of MOLM slightly improved energy content of thigh meat $(\mathrm{P}=0.004)$. Although the energy content of M3 group was not significantly different $(\mathrm{P}<0.05)$ from the control group, but it showed the lowest value when compared to other supplemented groups (M1 M5 and M7).

\section{TBA, Cholesterol and pH levels in Breast and Thigh Meat}

Supplementation of diets with MOLM resulted in a significant $(\mathrm{P}=0.001)$ depression in $\mathrm{pH}$ of breast meat. The lowest $\mathrm{pH}$ was observed in M3 and M5 groups, while $\mathrm{pH}$ values for $\mathrm{M} 1$ and $\mathrm{M} 7$ were similar $(\mathrm{P}<0.05)$ to the values observed in the control group (Table 3 ). On the other hand the supplementation of diets with MOLM did not affect the $\mathrm{pH}$ values of thigh meat $(\mathrm{P}=0.148)$. However, birds fed diet supplemented with 3\% MOLM showed numerically the lowest $\mathrm{pH}$ value.

The diet supplemented with MOLM reduced $(\mathrm{P}<0.001)$ the TBA values of breast meat (Table 4). Birds fed diet supplemented with 1\% MOLM showed a higher TBA value compared to those fed other experimental diets $(\mathrm{P}<0.05)$. Unlike breast meat, the TBA level in thigh meat was affected by MOLM in different way $(\mathrm{P}<0.001)$. In details, birds fed diets supplemented with 3\% MOLM 
Table 3: Meat $\mathrm{pH}$ of broilers as influenced by different dietary treatments

\begin{tabular}{lll}
\hline Groups & Breast meat & Thigh meat \\
\hline Con & $5.88 \pm 0.058 \mathrm{a}$ & $5.99 \pm 0.088$ \\
M1 & $5.89 \pm 0.061 \mathrm{a}$ & $6.16 \pm 0.058$ \\
M3 & $5.44 \pm 0.058 \mathrm{~b}$ & $5.90 \pm 0.057$ \\
M5 & $5.56 \pm 0.057 \mathrm{~b}$ & $5.95 \pm 0.088$ \\
M7 & $5.74 \pm 0.057 \mathrm{a}$ & $6.09 \pm 0.057$ \\
\hline
\end{tabular}

Control group fed basal diet without any supplementation. M1, M2, M3 and M4 groups fed basal diet supplemented with 1, 3, 5 and $7 \%$ MOLM, respectively. $\mathrm{P}$ values for breast and thigh meat were 0.001 and 0.148 , respectively. Mean+SD sharing no common alphabets in column are significantly different $(\mathrm{P}<0.05)$.

Table 4: TBA values (mg malondialdehyde $\mathrm{kg}^{-1}$ ) of broilers meat

\begin{tabular}{lll}
\hline Groups & Breast meat & Thigh meat \\
\hline Con & $0.482 \pm 0.059 \mathrm{~b}$ & $0.099 \pm 0.006 \mathrm{bc}$ \\
M1 & $1.087 \pm 0.058 \mathrm{a}$ & $0.176 \pm 0.004 \mathrm{~b}$ \\
M3 & $0.438 \pm 0.028 \mathrm{~b}$ & $0.347 \pm 0.060 \mathrm{a}$ \\
M5 & $0.345 \pm 0.057 \mathrm{~b}$ & $0.033 \pm 0.006 \mathrm{c}$ \\
M7 & $0.334 \pm 0.057 \mathrm{~b}$ & $0.104 \pm 0.005 \mathrm{bc}$
\end{tabular}

Control group fed basal diet without any supplementation. M1, M2, M3 and M4 groups fed basal diet supplemented with 1, 3, 5 and $7 \%$ MOLM, respectively. $\mathrm{P}$ value for breast and thigh meat was $<0.001$. Mean+SD sharing no common alphabets in column are significantly different $(\mathrm{P}<0.05)$.

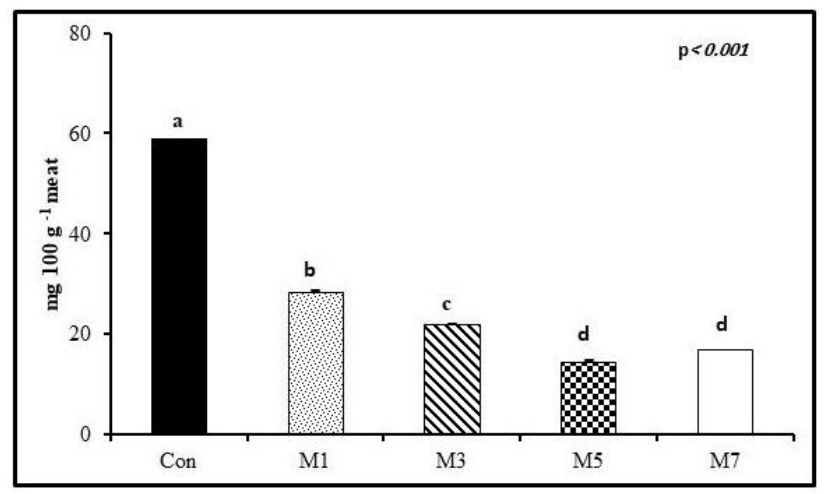

Fig 1: Cholesterol level $\left(\mathrm{mg} 100 \mathrm{~g}^{-1}\right)$ of breast meat of broilers chicken fed basal diet (Con) or M1, M2, M3 and M4 groups fed basal diet supplemented with 1,3,5 and 7\% MOLM, respectively. Bar+SD sharing no common alphabets are significantly different $(\mathrm{P}<0.05)$.

showed the highest TBA value, while the birds fed diet supplemented with 5\% MOLM $(\mathrm{P}<0.05)$ showed the lowest value in thigh meat.

Supplementation of diets with MOLM reduced cholesterol level in breast meat by $65 \%(\mathrm{P}<0.001)$. Birds fed diets supplemented with 5 and $7 \%$ MOLM had the lowest cholesterol level compared to other groups (Fig. 1). Cholesterol level in breast meat was in the order of $\mathrm{C}>\mathrm{M} 1>\mathrm{M} 3>\mathrm{M} 5=\mathrm{M} 7(\mathrm{P}<0.05)$.

\section{DISCUSSION}

Broiler chicken meat has a strong demand among consumers due to its high protein, minerals, and vitamin content, as well as its low-fat content. To increase customer satisfaction and preference for poultry meat, efforts are being made to enhance meat quality and storage capacity. Dietary manipulation is critical in improving the composition and quality of poultry meat in this context (Cheng et al. 2019; Santhi et al. 2020). In the current study, the effects of various inclusion levels of MOLM on the quality of broiler meat were investigated.

The DM and CP content in meat increased with the addition of MOLM to the diet, while fat content decreased. In the same context, it was reported that dietary supplementation of MO silage improved the CP content of lamb meat (Cohen-Zinder et al. 2017). This may be due to the capability of MOLM to improve protein absorption and retention (Lu et al. 2016). Since a high intake of fat is linked to increased risk of cardiovascular disease in humans, numerous studies have been published which showed how to minimize the fat content in meat. In the current study, the broiler receiving 3 and 5\% MOLM showed the decreased amount of fat in the carcass. The reduction in fat percentage could be attributed to difference in fat metabolism caused by supplementation of MOLM. Several reports showed that supplementation of MOLM decreased fat synthesis (Sangkitikomol et al. 2014) and inhibit fat accumulation by inhibiting the adipogenesis and promoting the lipolysis (Xie et al. 2018).

Nowadays, customers prefer low-fat diet in order to minimize the risk of heart disease. Recently, researchers have found a number of dietary supplements to produce poultry meat with a low cholesterol content (Ayerza and Lauria 2002; Chowdhury et al. 2002). However, there is still a scarcity of knowledge about alternative production methods that can help achieve this goal (Ponte et al. 2004). In the current study, cholesterol level was lower in all groups receiving MOLM than that of the control group, the group fed diet supplemented with 5\% MOLM showed the lowest cholesterol content. This may be attributed to the ability of MOLM to reduce the blood cholesterol level as reported by Alnidawi et al. (2016). Moreover, MO exhibited cholesterol lowering activities through reduction of intestinal uptake of dietary cholesterol (Jain et al. 2010; Maheshwari et al. 2014).

The $\mathrm{pH}$ value was measured in broiler meat at the day of slaughter, in experimental groups the $\mathrm{pH}$ value in breast muscle was significantly lower than that of the control group, $\mathrm{pH}$ value was the lowest in a group of broilers received 5\% MOLM. The amount of glycogen in the muscle before slaughter and the rate of glycogen conversion into lactic acid after slaughter decide the $\mathrm{pH}$ of broiler meat (Anadon 2002). In the current study, the high amount of glycogen in the supplemented groups may contribute to lower the $\mathrm{pH}$ in their muscles. Meat samples having $\mathrm{pH}$ above 5.8 spoiled quickly, exhibiting short durability (Price and Schweigert 1987). Our results showed that the diet supplemented with 5\% MOLM improved the shelf life of the breast muscle. This result agrees with a previous study conducted by Wapi et al. (2014) who reported that broilers supplemented with MOLM showed a decrease in $\mathrm{pH}$ on day 7 . Furthermore, the low $\mathrm{pH}$ value is a positive characteristic since low $\mathrm{pH}$ inhibited the growth of microorganism.

One of the commonly used methods as an indicator of lipid oxidation in the meat is TBA (Raharjo and Sofos 1993). The results of the current study showed that meat from birds fed diets supplemented with MOLM showed lower TBA values compared to non-supplemented group. The lipid peroxidation suppression was observed in the broiler meat samples from MOLM supplemented groups; this showed that birds defensive mechanism prevents the 
excessive formation of free radicals (Qwele et al. 2013). Moreover, the presence of vitamins A, C and E in MOLM further describe the reduction of lipid peroxidation but the mechanism behind this action still needs to be explained (Kou et al. 2018). Dietary supplementation of moringa leaves could be a possible strategy for improving the quality of broiler meat due to its anti-oxidant properties (Mahfuz and Piao 2019). Similarly, the highest inclusion level of MOLM in the diets decreased the TBA level. Nkukwana et al. (2014) reported the lowest TBA value in the breast meat at 2\% inclusion level of MOLM. This indicate that MOLM supplementation could improve the oxidative stability of broiler meat.

\section{Conclusion}

In conclusion, addition of MO leaves in the diet of broiler chicks improved chemical composition of meat specially $\mathrm{CP}$ content and meat quality. The lowest $\mathrm{pH}$ value was observed in broilers fed diets supplemented with $3 \%$ MO leaves. Additionally, the inclusion of MO leaves lowers the TBA values which indicate its potential to improve oxidative stability of broilers meat. Moreover, the addition of MO leaves reduces cholesterol level in the meat of broiler chickens which may have a positive effect on consumer health.

\section{Author's Contribution}

ABS and ESM conceived of the presented idea. SA carried out the experiment. SA and MM contributed to sample preparation. ESM and MM contributed to the statistical analysis and the interpretation of the results. ESM wrote the manuscript with support from ABS.

\section{Acknowledgements}

The authors would like to express their gratitude to the staff of Animal and Clinical Nutrition Department, Faculty of Veterinary Medicine, Assuit University for sample analysis and continuous support.

\section{REFERENCES}

Alagawany M, Elnesr S, Farag R, Abd El-Hack ME, Barkat RA, Gabr AA, Foda MA, Noreldin AE, Khafaga AF, El-Sabrout K, Elwan AMH, Tiwari R Yatoo MI, Michalak I, Di Cerbo A and Dhama K, 2021. Potential role of important nutraceuticals in poultry performance and health - A comprehensive review. Research in Veterinary Science 137: 9-29. https://doi.org/10.1016/j.rvsc.2021.04.009

Alnidawi A, Ali F, Abdelgayed S, Ahmed F and Farid M, 2016. Moringa Oleifera leaves in broiler diets: Effect on chicken performance and health. Food Science and Quality Management 58: 2224-2229.

Alwaleed S, Mickdam E, Ibrahim A and Sayed A, 2020. The effect of dried moringa oleifera leaves on growth performance, carcass characteristics and blood parameters of broiler chicken. SVU-International Journal of Veterinary Sciences 3: 87-99. https://doi.org/10.21608/SVU.2020. 20685.1038

Anadon HLS, 2002. Biological, nutritional, and processing factors affecting breast meat quality of broilers. Ph.D. Thesis, Virginia Polytechnic Institute and State University, Blacksburg, VA, 24061, USA.

AOAC, 2005. "Official Methods of Analysis". 18 ${ }^{\text {th }}$ Ed. Association of Official Analytical Chemists, Washinton, DC, USA.
Arshad MS, Anjum FM, Khan MI, Saeed F, Imran A and Sohaib M, 2016. Manipulation of natural antioxidants in feed to enhance the oxidative stability and quality of broiler breast meat and nuggets. Journal of Food Processing and Preservation 41: e12849. https://doi.org/10.1111/jfpp.12849

Ayerza R, Coates W and Lauria M, 2002. Chia seed (Salvia hispanica L.) as an $\omega-3$ fatty acid source for broilers: Influence on fatty acid composition, cholesterol and fat content of white and dark meats, growth performance and sensory characteristics. Poultry Science 81: 826-837. https://doi.org/10.1093/ps/81.6.826

Bligh EG and Dyer WJ, 1959. Rapid method of total lipid extraction and purification. Canadian Journal of Biochemistry and Physiology 37: 911-917.

Cheng YF, Chen YP, Li J, Qu HM, Zhao YR, Wen C and Zhou YM, 2019. Dietary ß-Sitosterol improves growth performance, meat quality, antioxidant status and mitochondrial biogenesis of breast muscle in broilers. Animals 9: 71. https://doi.org/10.3390/ani9030071

Chowdhury SR, Chowdhury SD and Smith TK, 2002. Effects of dietary garlic on cholesterol metabolism in laying hens. Poultry Science 81: 1856-1862. https://doi.org/10.1093/ ps/81.12.1856

Cohen-Zinder M, Orlov A, Trofimyuk O, Agmon R, Kabiya R, Shor-Shimoni E A Shabtay, 2017. Dietary supplementation of Moringa Oleifera silage increases meat tenderness of Assaf lambs. Small Ruminant. Research 151: 110-116. https://doi.org/10.1016/j.smallrumres.2017.04.021

Degla LH, Kuiseu J, Olounlade PA, Attindehou S, HounzangbeAdote MS, Edorh PA and Lagnika L, 2021. Use of medicinal plants as alternative for the control of intestinal parasitosis: Assessment and perspectives. Agrobiological Records 7: 19. https://doi.org/10.47278/journal.abr/2021.011

Dhakad AK, Ikram M, Sharma S, Khan S, Pandey VV and Singh A, 2019. Biological, nutritional, and therapeutic significance of Moringa oleifera Lam. Phytotherapy Research 33: 2870 2903. https://doi.org/10.1002/ptr.6475

Gehad AE, Mohamed MA, Emara MMT and Yassien NA, 2020. Effect of Moringa oleifera aqueous extracts on the physicochemical characteristics, microbiological quality and biogenic amines of semi-dry fermented sausage. International Journal of Veterinary Science 9: 285-290.

Gilani SMH, Rashid Z, Galani S, Ilyas S, Sahar S, Zahoor H, AlGhanim K, Zehra S, Azhar A, Al-Misned F, Ahmed Z, AlMulham N and Mahboob S, 2021. Growth performance, intestinal histomorphology, gut microflora and ghrelin gene expression analysis of broiler by supplementing natural growth promoters: A nutrigenomics approach. Saudi Journal of Biological Sciences 28: 3438-3447. https://doi.org/ 10.1016/j.sjbs.2021.03.008

Gupta S, Jain R, Kachhwaha S and Kothari SL, 2018. Nutritional and medicinal applications of Moringa oleifera Lam.Review of current status and future possibilities. Journal of Herbal Medicine 11: 1-11. https://doi.org/10.1016/j.hermed. $\underline{2017.07 .003}$

Haque MH, Sarker S, Islam MS, Islam MA, Karim MR, Kayesh MEH, Shiddiky MJA and Anwer MS, 2020. Sustainable antibiotic-free broiler meat production: Current trends, challenges, and possibilities in a developing country perspective. Biology 9: 411. https://doi.org/10.3390/ biology9110411

Hassan HMA, El-Moniary MM, Hamouda Y, El-Daly EF, Youssef AW and El-Azeem NAA, 2016. Effect of different levels of Moringa Oleifera leaves meal on productive performance, carcass characteristics and some blood parameters of broiler chicks reared under heat stress conditions. Asian Journal of Animal and Veterinary Advances 11: 60-66. https://doi.org/10.3923/ajava.2016. $\underline{60.66}$ 
Jain PG, Patil SD, Haswani NG, Girase MV and Surana SJ, 2010. Hypolipidemic activity of Moringa oleifera Lam. Moringaceae, on high fat diet induced hyperlipidemia in albino rats. Revista Brasileira De Farmacognosia-brazilian Journal of Pharmacognosy 20: 969-973. https://doi.org/ 10.1590/S0102-695X2010005000038

Kholif AE, Gouda GA, Anele UY and Galyean ML, 2018. Extract of Moringa oleifera leaves improves feed utilization of lactating Nubian goats. Small Ruminant Research 158: 6975. https://doi.org/10.1016/j.smallrumres.2017.10.014

Kou X., Li B, Olayanju JB, Drake JM and Chen N, 2018. Nutraceutical or pharmacological potential of Moringa oleifera Lam. Nutrients 10:343. https://doi.org/10.3390/nu1 0030343

Krauze M, Cendrowska-Pinkosz M, Matusevicius P, Stępniowska A, Jurczak P and Ognik K 2021. The effect of administration of a phytobiotic containing cinnamon oil and citric acid on the metabolism, immunity, and growth performance of broiler chickens. Animals 11: 399. https://doi.org/10.3390/ ani11020399

Lu W, Wang J, Zhang HJ, Wu SG and Qi GH, 2016. Evaluation of Moringa oleifera leaf in laying hens: Effects on laying performance, egg quality, plasma biochemistry and organ histopathological indices. Italian Journal of Animal Science 15: 658-665. https://doi.org/10.1080/1828051X.2016.1249967

Maheshwari K, Yadav RK, Malhotra J, Dhawan NG and Mohan L, 2014. Fascinating nutritional, prophylactic, therapeutic and socio-economic reconcile attributable to drum stick tree (Moringa oleifera Lam.). Global Journal of Medical research: B Pharma, Drug Discovery, Toxicology and Medicine 14: 11-22.

Mahfuz S and Piao XS, 2019. Application of Moringa (Moringa Oleifera) as Natural Feed Supplement in Poultry Diets. Animals 9: 431. https://doi.org/10.3390/ani9070431

Mahmoud H, Dawood MA, Assar MH, Ijiri D and Ohtsuka A, 2019. Dietary Moringa oleifera improves growth performance, oxidative status, and immune related gene expression in broilers under normal and high temperature conditions. Journal of Thermal Biology 82: 157-163. https://doi.org/10.1016/j.jtherbio.2019.04.016

Mehta K, Balaraman R, Amin AH, Bafna PA and Gulati OD, 2003. Effect of fruits of Moringa Oleifera on the lipid profile of normal and hypercholesterolaemic rabbits. Journal of Ethnopharmacology 86: 191-195. https://doi.org/10.1016/ $\underline{\text { S0378-8741(03)00075-8 }}$

Naeemi ED, Ahmed N, Al-Sharrah TK and Behbahani M, 1995. Rapid and simple method for determination of cholesterol in processed food. Journal of AOAC International 78: 15221525. https://doi.org/10.1093/jaoac/78.6.1522

Nkukwana TT, Muchenje V, Masika PJ, Hoffman LC, Dzama K and Descalzo AM, 2014. Fatty acid composition and oxidative stability of breast meat from broiler chickens supplemented with Moringa Oleifera leaf meal over a period of refrigeration. Food Chemistry 142: 255-261. https://doi.org/10.1016/j.foodchem.2013.07.059

Nkukwana TT, Muchenje V, Masika PJ, Pieterse E, Hoffman LC and Dzama K, 2015. Proximate composition and variation in colour, drip loss and $\mathrm{pH}$ of breast meat from broilers supplemented with Moringa oleifera leaf meal over time. Animal Production Science 56: 1208-1216. https://doi.org/ 10.1071/AN14055

Pasin G, Smith G and O'mahony M, 1998. Rapid determination of total cholesterol in egg yolk using commercial diagnostic reagent. Food Chemistry 61: 255-259. https://doi.org/ 10.1016/S0308-8146(97)00072-1

Ponte PIP, Mendes I, Quaresma M, Aguiar MNM, Lemos JPC, Ferreira LMA, Soares MAC, Alfaia CM, Prates JAM and
Fontes CMGA, 2004. Cholesterol levels and sensory characteristics of meat from broilers consuming moderate to high levels of alfalfa. Poultry Science 83: 810-814. https://doi.org/10.1093/ps/83.5.810

Prabakar G, Gopi M, Karthik K, Shanmuganathan S, Kirubakaran A and Pavulraj S, 2016. Phytobiotics: Could the greens inflate the poultry production. Asian Journal of Animal and Veterinary Advances 11: 383-392. https://doi.org/10.3923/ ajava.2016.383.392

Price JF and Schweigert BS, 1987. The science of meat and meat products. Food and Nutrtion Press, Trumbull, Conn., 3.

Qwele K, Muchenje V, Oyedemi S, Moyo B and Masika PJ, 2013. Effect of dietary mixtures of Moringa (Moringa Oleifera) leaves, broiler finisher and crushed maize on anti-oxidative potential of breast meat from broilers. African Journal of Biotechnology 12: 290-298. https://doi.org/10.5897/AJB12. $\underline{115}$

Raharjo S and Sofos JN, 1993. Methodology for measuring malonaldehyde as a product of lipid peroxidation in muscle tissues. Meat Science 35: 145-169. 1993. https://doi.org/ 10.1016/0309-1740(93)90046-K

Roth N, Käsbohrer A, Mayrhofer S, Zitz U, Hofacre C and Domig $\mathrm{KJ}, 2019$. The application of antibiotics in broiler production and the resulting antibiotic resistance in Escherichia coli: A global overview. Poultry Science 98: 1791-1804. https://doi.org/10.3382/ps/pey539

Sangkitikomol W, Rocejanasaroj A and Tencomnao T, 2014. Effect of Moringa Oleifera on advanced glycation endproduct formation and lipid metabolism gene expression in HepG2 cells. Genetics and Molecular Research 13: 723-735. http://dx.doi.org/10.4238/2014.January.29.3

Santhi D, Kalaikannan A and Natarajan A 2020. Characteristics and composition of emulsion-based functional low-fat chicken meat balls fortified with dietary fiber sources. Journal of Food Process Engineering 43: 1-12. https://doi.org/10.1111/jfpe.13333

Shin H, Prabhakaran V and Kim K 2018. The multi-faceted potential of plant-derived metabolites as antimicrobial agents against multidrug-resistant pathogens. Microbial Pathogenesis 116: 209-214. https://doi.org/10.1016/j. micpath.2018.01.043

Vyncke W, 1970. Direct determination of thiobarbituric acid value in trichloroacetic acid extracts of fish as a measure oxidative rancidity. Fette Seifen Anstrichmittel 72: 10841087. https://doi.org/10.1002/lipi.19700721218

Wapi C, Nkukwana TT, Hoffman LC, Dzama K, Pieterse E and Mabusela T, 2014. Physico-chemical shelf-life indicators of meat from broilers given Moringa Oleifera leaf meal. South African Journal of Animal Science 43: 43-47. https://doi.org/ 10.4314/sajas.v43i5.8

Xie J, Wang Y, Jiang WW, Luo XF, Dai TY, Peng L, Song S, Li LF, Tao T, Shi CY, Hao RS, Xiao R, Tian Y and Sheng J, 2018. Moringa Oleifera leaf petroleum ether extract inhibits lipogenesis by activating the AMPK signaling pathway. Frontiers Pharmacology 9: 1447. https://doi.org/10.3389/ fphar.2018.01447

Zanu HK, Asiedu P, Tampuori M, Abada M and Asante I, 2012. Possibilities of using moringa (Moringa Oleifera) leaf meal as a partial substitute for fishmeal in broiler chickens diets Journal of Animal and Feed Research 2: 70-75.

Zhang T, Si B, Tu Y, Cui K, Zhou C and Diao Q, 2019. Effect of including different levels of moringa (Moringa oleifera) leaf meal in the diet of finishing pigs: Performance, pork quality, fatty acid composition, and amino acid profile. Czech Journal of Animal Science 64: 141-149. https://doi.org/ 10.17221/204/2018-CJAS 